\title{
The spectrum of palpable breast lesions- A cytopathological study of 1193 cases
}

\author{
Manasa GC. ${ }^{1}$, Sneha SP. ${ }^{2}$, Govardhan . $^{3}$ \\ DOI: https://doi.org/10.17511/jopm.2021.i03.08 \\ 1* Manasa GC, MBBS, MD, Associate Professor, Department of Pathology, JJM Medical College, Davangere, Karnataka, India. \\ 2 Sneha SP, MBBS, Tutor, Department of Pathology, JJM Medical College, Davangere, Karnataka, India. \\ 3 Adicherla Govardhan, MBBS, Tutor, Department of Pathology, JJM Medical College, Davangere, Karnataka, India.
}

Introduction- The vast majority of the lesions that occur in the breast are benign. Much concern is given to malignant lesions of the breast because female breast cancer has now surpassed lung cancer as the leading cause of global cancer incidence in 2020. Fine needle aspiration cytology (FNAC) has good sensitivity, specificity and accuracy in the diagnosis of both neoplastic and nonneoplastic breast lump thereby assisting in early diagnosis and further management. The current study was done to study the incidence and the different cytomorphological patterns of palpable breast lumps by FNAC and consequently compare the results with studies in the literature. Materials and methods- This is a retrospective study conducted from January 2018 to December 2020 in a tertiary care hospital. The three-year data is obtained from the records maintained in the FNA clinic. The patients were counselled before the procedure and informed consent was taken. Results- A total of 1193 breast lump cases were analysed in this 3-year study, there were 19 male patients all of them presented with gynaecomastia and 1177 female patients. The patient's age group ranged from 12 to 86 years. The commonest age group with the lesions $31-40$ years comprising 326 cases (27.32\%) followed $21-30$ years age group in the second place with 307 cases $(25.7 \%)$. Conclusion- In this study the most common benign neoplastic and malignant neoplastic breast lumps are fibroadenoma and infiltrating ductal carcinoma respectively. Fibrocystic disease of the breast is the most common non-neoplastic breast lump.

Keywords: Breast, breast carcinoma, Fibroadenoma, Fibrocystic breast disease

Corresponding Author

Manasa GC, MBBS, MD, Associate Professor, Department of Pathology, JJM Medical College, Davangere, Karnataka, India.

Email: manasachandru@gmail.com

\section{How to Cite this Article}

Manasa GC, Sneha SP, Govardhan A. The spectrum of palpable breast lesions- A cytopathological study of 1193 cases. Trop J Pathol Microbiol. $2021 ; 7(3): 144-149$. Available From https://pathology.medresearch.in/index.php/jopm/ar ticle/view/521
To Browse

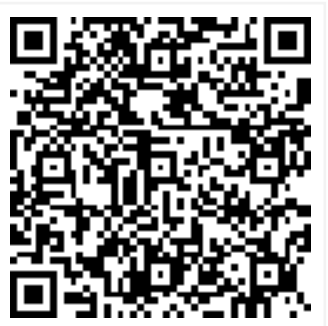

Manuscript Received 2021-03-04

Conflict of Interest No (c) 2021 by Manasa GC, Sneha SP, Adicherla Govardhan and Published by Siddharth Health Research and Social Welfare Society.
This is an Open Access article licensed under a Creative Commons Attribution 4.0 International License https://creativecommons.org/licenses/by/4.0/ unported [CC BY 4.0].
Review Round 2021-03-14

unding (1)

Review Round 2

2021-03-26

Tro

Accepted 2021-04-15 


\section{Introduction}

FNAC was used as a tool to confirm a clinical suspicion of carcinoma, its local recurrence or metastasis without subjecting the patient to further surgical intervention. This remains one of the most important contributions of the technique from a practical point of view. Following success in this area, the interest focused on the preliminary preoperative diagnosis of all kinds of neoplastic processes, benign or malignant, in any organ or tissue of the body and on definitive, specific diagnosis in inoperable cases as a guide to rational treatment.

This development is to a large degree the result of the consistent, continuous and critical correlation between cytological assessment and histopathological diagnosis facilitated by the organisational coordination of laboratory resources. [1]. Breast lesions are one of the common conditions referred for FNAC. Breast cytology is an important part of the "Triple approach" for preoperative diagnosis of breast lumps, along with clinical assessment and radiological imaging. The role of Fine needle aspiration cytology as a first-line investigation in diagnosing breast lesions is well documented.

Breast pathologies have a varied spectrum and range from developmental abnormalities, inflammatory lesions, and benign epithelial and stromal proliferation to various malignant neoplasms. The clinical presentation of these lesions encompasses a wide range of symptoms, the most common being palpable lumps or they may be incidental detection. [2,3]. The vast majority of the lesions that occur in the breast are benign. Much concern is given to malignant lesions of the breast because female breast cancer has now surpassed lung cancer as the leading cause of global cancer incidence in 2020, with an estimated 2.3 million new cases, representing $11.7 \%$ of all cancer cases. [4].

Breast cancer is now the most common cancer in Indian women, having recently overtaken cervical cancer.[5]. Breast cancer has ranked number one cancer among Indian females with an age-adjusted rate as high as 25.8 per 100,000 women. There is a significant increase in the incidence and cancerassociated morbidity and mortality in the Indian subcontinent as described in global and Indian studies. [6].
The Mortality-to-incidence ratio was found to be high in rural areas when compared to urban regions which may be because of prompt diagnosis and treatment. Besides this young age has been found as a major risk factor for breast cancer in Indian women. $[6,7]$. FNAC has good sensitivity, specificity and accuracy in the diagnosis of both neoplastic and non-neoplastic breast lump thereby assisting in early diagnosis and further management. [8]. A positive cytological diagnosis is possible in $75-80 \%$ of palpable cancers. Definitive treatment can often be based on the cytological diagnosis without the need for histological confirmation in centres with a large volume of cases and speciality trained cytopathologists unless there is a disagreement between cytology and clinical and/or mammographic assessment. [9]. The current study was done to study the incidence and the different cytomorphological patterns of patients with palpable breast lumps by FNAC and consequently compare the results with studies in the literature.

\section{Material and methods}

This study is conducted in tertiary care hospital. The study is a retrospective study conducted from January 2018 to December 2020. The three-year retrospective data is obtained from the records maintained in the FNA clinic. A total of 1193 breast lump cases were studied.

Inclusion criteria: All cases of palpable breast mass referred for FNA cytology with or without the radiological diagnosis.

Exclusion criteria: Cases with inadequate aspirate samples were excluded from the study. All cases presenting with palpable breast mass, which were referred to the FNA clinic were considered. Details about the relevant history, clinical examination and any radiological investigations done were collected from the FNA requisition form.

After obtaining a detailed history followed by clinical examination, a Routine FNA procedure under aseptic conditions was performed using 22-24G needles attached to a $10 \mathrm{cc}$ syringe. The skin over the breast lump was cleaned with a spirit cotton swab. The lesion was fixed with one hand, a 23G needle was inserted into the lesion with a $10 \mathrm{ml}$ syringe attached to it. The piston of the syringe was withdrawn to apply negative pressure; the needle was moved back and forth, in different directions within the lesion. Aspirated material was collected on glass slides and smears were prepared. 
A minimum of 3 smears was made depending on the amount of the aspirate obtained. Two smears were fixed in $95 \%$ ethyl alcohol and stained with Papanicolaou and Hematoxylin and Eosin ( $H \& E$ ) stains and one smear was air-dried and stained with Giemsa stain. These smears are initially inspected and the provisional diagnosis was made by the residents posted in the cytopathology unit, final reports were then given by the cytopathologist with a minimum of 2 years of experience. In malignant and in doubtful cases a consensus report was given after consulting another cytopathologist. Ethical clearance has been obtained from the institution where the study is conducted. All the cases were analysed by obtaining the impression from the records; in case of doubt the smears were rescreened.

The data obtained regarding various variables and the final diagnosis was tabulated using Microsoft excel, and further analysis is undertaken. Data are presented as mean, range, and percentages.

\section{Results}

A total of 1193 breast lump cases were analysed in this 3-year study, there were 19 male patients all of them presented with gynaecomastia and 1177 female patients.

The patient's age group ranged from 12 to 86 years. The commonest age group (Table 1 ) with the lesions $31-40$ years comprising 326 cases (27.32\%) followed $21-30$ years age group in the second place with 307 cases (25.7\%).

Table 1. FNAC of breast lesions: age distribution

\begin{tabular}{|l|l|l|}
\hline \multicolumn{1}{|c|}{ Age group (years) } & \multicolumn{1}{|c|}{ Number of cases } & \multicolumn{1}{c|}{ Percentages } \\
\hline $10-20$ & 141 & $11.81 \%$ \\
\hline $21-30$ & 307 & $25.7 \%$ \\
\hline $31-40$ & 326 & $27.32 \%$ \\
\hline $41-50$ & 221 & $18.5 \%$ \\
\hline $51-60$ & 118 & $9.89 \%$ \\
\hline$>60$ & 80 & $6.7 \%$ \\
\hline Total number of cases & 1193 & \\
\hline
\end{tabular}

Considering the cytomorphological spectrum (Table 2), among 19 male patients all of them presented with gynecomastia, in females neoplastic (including both benign and malignant) breast lesions (77.73\%) were more common than non-neoplastic breast $(22.27 \%)$ lesions. In the neoplastic lesions, the benign neoplastic lesions (644 cases) were more than malignant tumors (283 cases).
Benign neoplastic lesions were all fibroadenomas 4 cases of fibroadenoma were bilateral. In our study, there were also 13 cases of ductal papilloma reported. In the malignant category out of 283 cases 26 cases were reported as suspicious for malignancy, 251 cases were of ductal carcinoma out of which 12 cases showed axillary lymph node metastasis. Out of the remaining 6 cases 3 were mucinous carcinoma, one was a plasmacytoid variant of carcinoma and 2 were categorized as metaplastic carcinoma. In non-neoplastic lesions, the most commonly found lesion was fibrocystic disease (121 cases). In the inflammatory breast lesions, 52 cases of acute mastitis and 65 cases of granulomatous mastitis 24 cases of galactocele $(1.6 \%)$ in postpartum females and 4 lesions of duct ectasia were diagnosed.

Table-2: FNAC of breast lesions: cytomorphological spectrum

\begin{tabular}{|c|c|c|}
\hline Breast lesions & Number of cases & Percentage $\%$ \\
\hline \multicolumn{3}{|l|}{ Non-neoplastic breast lesions } \\
\hline Acute mastitis & 52 & $4.35 \%$ \\
\hline Granulomatous mastitis & 65 & $5.44 \%$ \\
\hline Galactocele & 24 & $2.01 \%$ \\
\hline Duct ectasia & 4 & $0.33 \%$ \\
\hline Fibrocystic disease & 121 & $10.14 \%$ \\
\hline \multicolumn{3}{|l|}{ Neoplastic breast lesions } \\
\hline \multicolumn{3}{|l|}{ Benign } \\
\hline Fibroadenoma & 518 & $43.41 \%$ \\
\hline Phyllodes & 30 & $2.51 \%$ \\
\hline Benign epithelial hyperplasia/Atypical & 64 & $5.36 \%$ \\
\hline Intraductal papilloma & 13 & $1.08 \%$ \\
\hline gynaecomastia & 19 & $1.59 \%$ \\
\hline \multicolumn{3}{|l|}{ Malignant } \\
\hline Suspicious for malignancy & 26 & $2.17 \%$ \\
\hline Infiltrating ductal carcinoma & 257 & $21.5 \%$ \\
\hline Total number of cases & 1193 & \\
\hline
\end{tabular}

\section{Discussion}

In the present study, we included 1193 breast lump cases. The inadequate samples were excluded from the study. In our study, the youngest patient was 12 years old and the oldest was 86 years old female. The majority of the cases with palpable breast lumps occurred in females between third to fifth decades of life age group where the majority of physiological changes takes place (both progressive and regressive) altered or diverted physiological change may end up in the pathological lesions, these finding of ours is in correlation with studies by Chamdanwale et al. Rachana et al. \& Likhar et al. 


\section{$[10,11,12]$.}

The triad of a cellular smear with a bimodal benign pattern, numerous single bipolar oval nuclei and fragments of the stroma is virtually diagnostic of fibroadenoma. In the absence of stroma, numerous single bipolar nuclei are highly suggestive of the diagnosis. In the present study, fibroadenoma was the most common benign lesion which was seen most commonly in the younger $[13,14,15]$. The bimodal pattern of cohesive groups of epithelial cells and scattered single, bare, bipolar nuclei was the common finding in most benign smears.

Smears with stromal cellularity, atypia and mitotic activity define whether a phyllodes tumor is benign, low grade or high grade. Smears with increased stromal cellularity were labelled as phyllodes tumor. Out of 16 cases reported as phyllodes tumor in our study none of them showed nuclear atypia or mitotic activity. Among benign lesions there were also 64 cases of ductal hyperplasia which included both benign and atypical.

The benign ductal epithelial hyperplasia smears showed cell-rich smears, large sheets of cohesive epithelial cells, few single cells often in a 'streaming' pattern; focal crowding and overlapping of nuclei, Nuclear atypia absent Naked bipolar and myoepithelial nuclei present. Atypical ductal hyperplasia showed similar cellularity with mild to moderate nuclear atypia and few myoepithelial cells in the background. 13 cases of ductal papilloma were reported, which on smears showed complex folded and branching epithelial sheets and fingerlike fragments, strands of fibrovascular stroma cores.

Maximum numbers of malignant cases were above the age group of 41 to 50 years which is similar to the results by Rachana et al. and Khan et al. [11, 16]. In the malignant category, 251 cases were of ductal carcinoma out of which 12 cases showed axillary lymph node metastasis while a study performed by Rahman MZ et al. showed $10.32 \%$ of malignant cases with metastatic lymph nodes on FNAC. [17].

Smears of malignant cases showed moderately to highly cellular smears with loss of cell cohesion arranged in irregular clusters and single cells, Moderate to severe nuclear atypia: enlargement, pleomorphism, irregular nuclear membrane and chromatin, Fibroblasts and fragments of collagen (stromal desmoplasia) were seen in many cases.
Out of the remaining 6 cases, 3 were mucinous carcinoma which showed moderately cohesive epithelial cells with abundant cytoplasm and moderate nuclear enlargement and atypia with abundant background mucin, one was a plasmacytoid variant of carcinoma a differential of plasmacytoma was also rendered in this 60 year old female and 2 were categorized as metaplastic carcinoma of which smears showed squamous differentiation along with high-grade carcinoma.

In the inflammatory category of breast lesions, we observed 52 cases of acute mastitis of which smears showed benign bimodal component of nonneoplastic breast tissue, acute inflammatory cells and few of them showed regenerative epithelial atypia, and 65 cases of granulomatous mastitis, the smears showed histiocytes, epithelioid cells, multinucleated giant cells and plasma cells along with non-neoplastic breast tissue. All the cases of granulomatous mastitis were negative for acid-fast bacilli in ZN stain few cases which showed caseating necrosis were referred for NAT testing for tuberculosis.

There were 24 cases of galactocele which had milky aspirate and the smears showed benign ductal epithelial cells abundant fragile cytoplasm with secretory vacuoles and frayed borders. In 4 cases of duct ectasia, the diagnosis of duct ectasia was rendered to the lesions located in the subareolar region smears showing chronic inflammatory cells along with the sheets of ductal epithelial cells. There were 121 cases of fibrocystic diseases of which 16 cases had bilateral lesions, the smears showed varied features comprised of epithelial fragments of benign ductal epithelial cells, scattered single bare bipolar/oval nuclei, the background of variable amounts of cyst fluid, macrophages, and apocrine metaplastic cells.

Fibrocystic diseases accounted for the majority of non-neoplastic lesions of the breast. A positive cytological diagnosis is possible in $75-80 \%$ of palpable cancers. Definitive treatment can be offered based on the cytological diagnosis without the need for histological confirmation in centres with a large volume of cases and speciality trained cytopathologists unless there is a disagreement between cytology and clinical and/or mammographic assessment. Approximately $98 \%$ of palpable masses with unequivocally malignant FNAC are invasive cancers, the remaining few are highgrade Ductal carcinoma in situ. [18]. 
Studies that compared FNAC to core needle biopsy for palpable breast carcinoma showed a higher sensitivity (97.5\% vs. $90 \%$ ) for FNAC regardless of the size of the tumour, its subtype or its degree of differentiation. [19].

\section{Conclusion}

In this study the most common benign neoplastic and malignant neoplastic breast lumps are fibroadenoma and infiltrating ductal carcinoma respectively. Fibrocystic disease of the breast is the most common non-neoplastic breast lump.

Many studies in the literature provide evidence that in palpable breast lump cytology reports done on the satisfactory smears by expertise could yield superior diagnostic results, and a significant advantage of FNAC is the low cost and the ability to render a diagnosis to the clinician and patient at the time of the procedure thus allowing treatment decisions to be made immediately.

The success of FNAC depends on if the sample is taken from the representative area of the lesion examined, if samples are adequate in terms of cells and other tissue components. If samples are correctly smeared and processed and accompanied by sufficient and correct clinical/radiological information.

\section{What does this study add to existing knowledge?}

The success of FNAC depends on if the sample is taken from the representative area of the lesion examined, if samples are adequate in terms of cells and other tissue components.

\section{Author contribution}

Manasa GC: Conception or design of the work, Data analysis and interpretation.

Sneha SP: Data collection, Drafting the article.

Adicherla Govardhan: Data collection.

\section{Reference}

01. Bedrossian CW. Bridging the gap between cytopathology and surgical pathology. Diagn Cytopathol. 1995 Feb;12(1)1-2. doi: 10.1002/dc.2840120102 [Crossref][PubMed] [Google Scholar]
02. Godwins, Echejoh, Dzuachi David, and Jenrola Akeem. "Histopathologic analysis of benign breast diseases in Makurdi, North Central Nigeria". International Journal of Medicine and Medical Sciences. 2011;3(5)125-128. [Crossref][PubMed] [Google Scholar]

03. Guray M, Sahin AA. Benign breast diseasesclassification, diagnosis, and management. Oncologist. 2006 May;11(5)435-49. doi: 10.1634/theoncologist.11-5-435 [Crossref] [PubMed][Google Scholar]

04. Sung $H$, Ferlay J, Siegel RL, Laversanne $M$, Soerjomataram I, Jemal A, et al. Global Cancer Statistics 2020- GLOBOCAN Estimates of Incidence and Mortality Worldwide for 36 Cancers in 185 Countries. CA Cancer J Clin. 2021 May;71(3)209249. doi: 10.3322/caac.21660 [Crossref][PubMed] [Google Scholar]

05. Gupta S. Breast cancer- Indian experience, data, and evidence. South Asian J Cancer. 2016 JulSep;5(3)85-6. doi: 10.4103/2278-330X.187552 [Crossref][PubMed][Google Scholar]

06. Malvia S, Bagadi SA, Dubey US, Saxena S. Epidemiology of breast cancer in Indian women. Asia Pac J Clin Oncol. 2017 Aug;13(4)289-295. doi: 10.1111/ajco.12661 [Crossref][PubMed][Google Scholar]

07. Anders CK, Hsu DS, Broadwater G, Acharya CR, Foekens JA, Zhang $Y$, et al. Young age at diagnosis correlates with worse prognosis and defines a subset of breast cancers with shared patterns of gene expression. J Clin Oncol. 2008 Jul 10;26(20)3324-30. doi: 10.1200/JCO.2007.14.2471 [Crossref][PubMed][Google Scholar]

08. Koss, L. "Diagnostic cytology 4th edition". (1992)6-11. [Crossref][PubMed][Google Scholar]

09. Orell, Svante R, Gregory F Sterrett, Daniel Whitaker. Fine needle aspiration cytology. Elsevier Churchill Livingstone. 2005. [Crossref][PubMed] [Google Scholar]

10. Chandanwale SS, Gupta K, Dharwadkar AA, Pal $\mathrm{S}$, Buch AC, Mishra N. Pattern of palpable breast lesions on fine needle aspiration- $A$ retrospective analysis of 902 cases. J Midlife Health. 2014 Oct;5(4)186-91. doi: 10.4103/0976-7800.145164 [Crossref][PubMed][Google Scholar] 
11. Rachana B, Shweta D, Mayur A, Grace DC. Cytomorphological spectrum of breast lesions diagnosed by fine needle aspiration cytology. International Journal of Medical and Health Research. 2018;4(8)168-71. [Crossref][PubMed] [Google Scholar]

12. Likhar K S, Fatima A, Hazari R A, Gupta S G, Shukla U. Diagnostic role of FNAC in breast lesions. IJRRMS. 2013;3(1)12-4. [Crossref][PubMed][Google Scholar]

13. Kamra H T, Rana P, Kaur S, Verma S, Munde $S$, et al. Spectrum of breast lesions diagnosed on fine needle aspiration cytology in rural population of Khanpur Kalan, Sonepat (Haryana). Ann Int Med Den Res. 2013;3(3)06-09. [Crossref][PubMed] [Google Scholar]

14. Akhator, Afeyodion. "Benign breast masses in Nigeria. " Nieg Jr of Surg Sciences. 17(2007)105-8. [Crossref][PubMed][Google Scholar]

15. Irabor D O, C A Okolo. "An audit of 149 consecutive breast biopsies in Ibadan, Nigeria. " Pakistan Journal of Medical Sciences. 2008;24(2)257. [Crossref][PubMed][Google Scholar]
16. Khan $A$, Jamali $R$, Jan $M$, Tasneem $M$. Correlation of fine needle aspiration cytology and histopathology diagnosis in the evaluation of breast lumps. International Journal of Medical Students. $2014 ; 2(2) 40-43$.

[Crossref][PubMed][Google Scholar]

17. Rahman MZ, Sikder AM, Nabi SR. Diagnosis of breast lump by fine needle aspiration cytology and mammography. Mymensingh Med J. 2011 Oct;20(4)658-64. [Crossref][PubMed][Google Scholar]

18. Chhieng DC, Fernandez G, Cangiarella JF, Cohen JM, Waisman J, Harris MN, et al. Invasive carcinoma in clinically suspicious breast masses diagnosed as adenocarcinoma by fine-needle aspiration. Cancer. 2000 Apr 25;90(2)96-101. [Crossref][PubMed] [Google Scholar]

19. Ballo MS, Sneige N. Can core needle biopsy replace fine-needle aspiration cytology in the diagnosis of palpable breast carcinoma- A comparative study of 124 women. Cancer. 1996 Aug $15 ; 78(4) 773-7 . \quad$ doi: 10.1002/(SICI)10970142(19960815)78:4<773::AID-

CNCR13>3.0.CO;2-S [Crossref][PubMed][Google Scholar] 